\title{
Del culto a la laboriosidad a la preocupación por la fatiga: dos miradas sobre la pobreza (Argentina, 1903-1904)
}

Sandra Caponi*

Resumo: este artigo analisa dois modos de olhar o mundo da pobreza que coexistiram num mesmo momento histórico (1903-1904) e num mesmo local geográfico (Argentina). O olhar do José Ingenieros, que contou com o reconhecimento da intelectualidade argentina, e a do Bialet Massé, que permaneceu virtualmente desconhecido por quase quarenta anos. Cada um destes autores apresenta um modo peculiar de abordar o corpo dos trabalhadores. José Ingenieros constrói um discurso sobre a pobreza centrado no tema da preguiça, particularmente, a preguiça do crioulo. Bialet Massé, por sua parte no texto denominado Informe sobre o estado da classe operária de 1904, apresenta um novo olhar sobre o corpo dos trabalhadores, centrado no problema da fadiga. Analisamos as diferenças entre estes discursos a partir do texto de Anson Rabinbach: Human Motor.

Palavras-chave: preguiça; fadiga; corpo; trabalho; raça.

Abstract: this article discusses two perspectives on poverty that coexisted in the period of 1903-1904 in the same geographic location (Argentina). The perspective outlined by José Ingenieros, whose ideas won the recognition of Argentina intelligentsia, and that of Bialet Massé point of view, which remained virtually unknown for nearly forty years. Each of those authors had peculiar analysis regarding the body of workers. José Ingenieros constructed a speech on poverty centered on the very trite theme of laziness, particularly: Creole laziness. Meanwhile, Bialet Massé, in his Report on the state of the working class of 1904, presented a view of the body of workers that, in that time, was very innovative. It was focused on the problem of fatigue. We analyze the differences between these speeches having as main reference the work of Anson Rabinbach: Human Motor.

Keywords: labor; body; race; fatigue; laziness.

* Doutora em Filosofia. Professora do Departamento de Sociologia e Ciências Políticas - Universidade Federal de Santa Catarina - Investigadora do CNPq. E-mail: sandracaponi@gmail.com. 
El mayor goce sensible, en estado de salud, es el reposo después del trabajo.

La propensión al reposo sin trabajo anterior, en el mismo estado, es la pereza. ${ }^{1}$

Las ciencias sociales argentinas nacieron signadas por las urgencias de un imperativo sarmientino: instaurar el dominio de una humanidad dócil, industriosa y civilizada allí donde reinaba la ociosa barbarie del desierto. La producción de esa humanidad laboriosa requería que toda una red de discursos e instituciones atravesara el cuerpo social a fin de hacer que los sujetos ociosos se transformaran en sujetos normales y productivos. Tal como Hugo Vezzetti ${ }^{2}$ u Oscar Terán ${ }^{3}$ lo han sabido mostrar, en Argentina, la emergencia de las ciencias humanas es deudora de esos discursos intermediarios entre la medicina y el derecho que Foucault se ocupó de cartografiar.

Así, esos estudios sociales que van desde "Las Bases" de Alberdi, ${ }^{4}$ hasta la "Sociología Argentina" de José Ingenieros," pasando por las "Multitudes Argentinas" de Ramos Mejía, ${ }^{6}$ parecen situarse en ese mismo diagrama de poder en el interior del cual los filántropos y los humanistas europeos edificaron saberes e instituciones médico-correctivas. La ambición de Bentham parece reiterarse en los teóricos argentinos de entonces: "Hacer que la escoria se convierta en plata", modelar el cuerpo y el alma de los individuos vistos como peligrosos: nos solo locos y criminales, sino también los criollos considerados como perezosos y temibles.

Para los "humanistas" europeos las categorías de anormalidad y peligrosidad se asociaban al horror que, ya en la época clásica, producía la sola mención de la pereza u ociosidad. Mientras el trabajo era pensado como el instrumento privilegiado de "normalización” y “moralización", la ociosidad remitía al orden de lo patológico, a un desvío mórbido que podía tener consecuencias catastróficas para los individuos y las razas. Será en torno al valor moralizador y normalizador del trabajo, y al terror que inspiraba su "otro", la pereza, que en las últimas décadas del siglo XIX y las primeras décadas del siglo XX, convergieron discursos como la medicina legal, la criminología, la higiene, la psiquiatría, la administración del trabajo y la sociología.

Ese mismo discurso referido al valor moralizador del trabajo y al desvío mórbido representado por la pereza, está presente en los argumentos defendidos por gran parte de los intelectuales argentinos de fines del siglo XIX e inicios del siglo XX7. No existe, sin embargo, una aceptación monolítica de ese discurso como es posible observar cuando analizamos el Informe sobre el estado de la clase obrera, realizado por Bialet Massé en 1904. En ese marco, propongo analizar dos miradas sobre la pobreza que coexisten en un mismo momento histórico y en un mismo lugar geográfico. Esto es, en Argentina en los años 1903 y 1904.

El objetivo de este artículo es analizar dos estrategias argumentativas referidas al mundo del trabajo que son claramente opuestas: los argumentos defendidos por José Ingenieros, prestigioso psiquiatra e sociólogo que gozaba

\footnotetext{
KANT, Immanuel (1798). Antropología en sentido pragmático. Madrid: Alianza Ed., 1991.

VEZZETTI, Hugo. La locura en la Argentina. Buenos Aires: Ed. Paidos, 1988.

TERÁN, Oscar. Positivismo y nación en la Argentina. Buenos Aires: Ed. Paidos, 1987.

ALBERDI, Juan Bautista. Organización de la Conferencia Argentina. Buenos Aires: El Ateneo, 1913.

INGENIEROS, José (1903). La simulación de la locura. In: Obras Completas. Buenos Aires: Ed. Mar Océano, 1961.

6 RAMOS MEJIA, José Maria. Las multitudes argentinas. Buenos Aires:Ed. Tor, 1965.

7 MIRANDA, Marisa; VALLEJO, Gustavo. Una historia de la Eugenesia, Argentina y las redes biopoliticas internacionales. Buenos Aires: Biblos, 2012.
} 
del reconocimiento de la intelectualidad argentina, y el estudio de Bialet Massé, ${ }^{8}$ médico e ingeniero cuyo trabajo permaneció prácticamente desconocida por casi cuarenta años. Existe una extensa literatura dedicada a la relectura de los trabajos de José Ingenieros, ${ }^{9}$ y en un número menor, algunos estudios recientes se dedicaron a analizar el trabajo de Bilaet Massé. ${ }^{10}$ Sin embargo, no existen estudios dedicados a analizar las diferencias teóricas y conceptuales que existen entre ambos, específicamente, en lo que se refiere al modo como cada uno de ellos problematiza el mundo del trabajo. Por ese motivo, este artículo propone analizar las diferencias existentes en el modo como José Ingenieros y Bialet Massé tematizan el cuerpo de los trabajadores.

Mientras José Ingenieros construye un discurso sobre la pobreza centrado en el tema de la pereza, particularmente, en lo que considera la pereza del criollo, Bialet Massé, presenta una mirada muy innovadora sobre el cuerpo de los trabajadores, que ya no se centra en el problema de la pereza sino en la cuestión de la fatiga. Para poder analizar las diferencias entre estos discursos, recurriremos al texto clásico de Anson Rabinbach"1 denominado Human Motor.

Como veremos, José Ingenieros parecía estar obcecado por la pereza del criollo y por la cuestión racial, ambos temas vinculados a una mirada negativa sobre los trópicos, cargada de lo que aquí denominaremos como pesimismo climático. Bialet Massé, al contrario, por medio de observaciones, entrevistas y cálculos llega a conclusiones absolutamente diferentes sobre el mundo de los trabajadores. Sus observaciones lo llevaron a abandonar la obsesión por la pereza y a construir argumentos capaces de derribar el mito persistente de la pereza del criollo o del nativo. Esos argumentos incansablemente repetidos por autores como Ramos Mejía o José Ingenieros, situaban a la pereza como contracara patológica de una verdadera "mitología del trabajo asalariado, que se fundaba en la proyección de su acción a una dimensión moral universal que lo enlaza, a la vez, a los registros de la pasión y el orden, de la creación y la virtud ciudadana". ${ }^{12}$

Como veremos, la asociación pereza-raza es heredera del discurso de los degeneracionistas europeos, preocupados por impedir los procesos de degradación de la especie. Tal como lo explicaron Morel $^{13}$ y Magnan, ${ }^{14}$ la degeneración, afectaría no solo a los individuos y a su descendencia inmediata sino también, a las generaciones sucesivas, llevando a la decadencia de las razas. Ese proceso estaría directamente asociado a los efectos indeseables de la pereza y la ociosidad, que los degeneracionistas asociaban a hechos sociales como el alcoholismo, la prostitución o el uso de tóxicos..$^{15}$ Por otra parte, se trata de un proceso que está

8 BIALET MASSÉ, Juan (1904). Informe sobre el estado de la clase obrera. Madrid: Hispamérica, 1985.

9 TERAN. Positivismo y nación; VEZZETTI. La locura en la Argentina; BIAGINI, Héctor. El movimiento positivista argentino. Buenos Aires: Ed Belgrano, 1980; VERMEREN, Patrice y VILLAVICENCIO, Susana. "Positivismo y ciudadanía: José Ingenieros y la constitución de la ciudadanía por la ciencia y la educación en la Argentina”. Anuario de Filosofía Argentina y Americana, n 15, año 1998, p. 61-78; STAGNARO, Juan Carlos. "Evolución y Situación de la Historiografía de la psiquiatría Argentina”. Rev Frenia, Vol VI, № 1, 2006; FERNANDEZ, Cristina Beatriz. "¿Teorías científicas fuera de lugar? Algunas derivas del evolucionismo en el positivismo argentino". Hispanic Research Journal, vol. 7, No. 3, September 2006, p. 223-236.

10 TRIMBOLI, Javier. Mil novecientos cuatro por el camino de Bialet Massé. Buenos Aires: Ediciones Colihue, 1999; CAMPI, Daniel. A cien años del Informe Bialet Massé. San Salvador de Jujuy: Universidad Nacional de Jujuy, 2004; ROLDAN, Diego. "Discursos alrededor del cuerpo, la máquina, la energía y la fatiga: hibridaciones culturales en Argentina fin-de-siècle". Revista História, Ciência e Saúde - Manguinhos, v. 17, nº 3, 2010.

11 RABINBACH, Anson. The human motor. New York: B. Books, 1991.

12 VEZZETTI. La locura en la Argentina, p. 95.

13 MOREL, Benedict. Traité des dégénérescence de l'éspèce humaine. Paris: Baillére, 1857.

14 MAGNAN, Valentin. Leçons cliniques sur les maladies mentales. Paris: Baillére, 1887.

15 CAPONI, Sandra. Loucos e Degenerados: uma genealogía da psiquiatría ampliada. Rio de Janeiro: Fiocruz, 2014. 
atravesado por un discurso que defiende tanto la jerarquización de razas, como la necesidad de una supuesta mejora racial.

\section{Pereza y fatiga}

En un horizonte discursivo completamente diferente de aquel centrado en el eje pereza-raza debemos situar al Informe sobre el estado de la clase obrera argentina que Juan Bialet Massé presenta, en el año 1904, para servir de base a una reforma de la legislación laboral proyectada por Joaquín V. González. Una reforma que, lamentablemente, no será realizada sino muchos años más tarde. Este Informe, que carga con el peso del momento histórico en que fue realizado, respondiendo al Decreto Presidencial del 15 de enero de 1904, del segundo gobierno conservador de J. A. Roca, está atravesado por contradicciones en lo que se refiere a las propuestas de reforma de la legislación laboral. ${ }^{16}$

No será objeto de este escrito analizar la discusión sobre la legislación laboral argentina. Propongo, en cambio, observar el modo como Bialet Massé problematiza la existencia cotidiana de los trabajadores, particularmente la mirada médica y sociológica que dirige al cuerpo de quien trabaja. A modo de presentación de su estudio, dirá:

Mi modo de proceder, en el desempeño de esta comisión, ha sido el mismo que he empleado antes. Ver el trabajo en la fábrica, en el taller o en el campo, tomar los datos sobre él y después ir a buscar al obrero en su rancho o en el conventillo, sentir con él, ir a la fonda, a la pulpería, a las reuniones obreras, oírle sus quejas; pero también oír a los patrones y capataces. En los ferrocarriles he pedido datos a los gerentes, he ido a los talleres, y al viajar en los trenes, me he bajado en cada estación, para ver el servicio, y donde lo he creído necesario he viajado en los trenes de carga, aprovechando las largas paradas en las estaciones. He penetrado en el toldo del indio y recorrido los puestos de las estancias. ${ }^{17}$

Durante cuatro meses, Bialet Massé recorrerá ese mundo complejo habitado por trabajadores, desempleados, empresarios y capataces. A ellos dirigirá la mirada de un médico, que partiendo de los más recientes conocimientos de fisiología, nutrición y fisiopatología, será capaz de determinar con cierta precisión el déficit nutricional o la carga excesiva de esfuerzo que un operario está obligado a realizar, sin dejar de considerar las condiciones ambientales existentes en cada caso. Elementos como el calor, la humedad, la falta de oxigeno imponen ciertas limitaciones a los cuerpos que deberán ser cuidadosamente evaluadas en cada caso.

Al mismo tiempo, este Informe presenta las observaciones de un sociólogo que fue capaz de realizar entrevistas y observaciones sistemáticas referidas, por ejemplo, al conocimiento que los patrones y capataces tienen sobre las tareas que imponen a sus obreros. Estudia la vida cotidiana de los trabajadores, su tiempo de trabajo y descanso, el modo como ocupan el tiempo libre, las solidaridades entre pares, utilizando entrevistas realizadas a patrones y obreros, ya sea sobre cuestiones de carácter general o sobre cuestiones específicas referidas a la atención médica, a los horarios de trabajo, tiempo libre y tipo de alimentación.

16 RECALDE, Hector. "Prólogo". In: Informe sobre el estado de la clase obrera. Buenos Aires: Ed. Ministerio de la Provincia de Buenos Aires, 2010.

17 BIALET MASSÉ. Informe sobre el estado de la clase obrera, p. 14. 
Por fin, el Informe presenta otra mirada peculiar: la que el autor dirige ya no en su carácter de médico, abogado o sociólogo al mundo de los trabajadores, sino como siendo él mismo, un trabajador más. Bialet Massé se propone describir el estado de fatiga que siente en su propio cuerpo al realizar determinados trabajos, describir el peso de las tareas realizadas a partir de la observación de sus propios movimientos y de su propio cuerpo. Así, aún contando con 58 años de edad en el momento en que realiza los estudios para su Informe, Bialet Massé dirá:

Donde he podido y mis fuerzas o mis conocimientos han alcanzado, he tomado las herramientas y hecho el trabajo por mí mismo, para sentir las fatigas; así he entrado en las bodegas de los buques, he pasado un día y otro al lado de las trilladoras y tomado la guadaña para cortar alfalfa y hecho medio jornal sentado en la segadora, al rayo del sol, en mangas de camisa. ${ }^{18}$

Lo cierto es que, con este Informe emerge un nuevo modo de entender el cuerpo de los trabajadores, un abordaje capaz de romper con los estereotipos repetidos hasta el hartazgo por la intelectualidad argentina de la época. Fundamentalmente, porque se niega a reproducir los mitos argentinos de la pereza de las clases pobres en general y del indígena, del criollo o del nativo, en particular. Un mito que sus contemporáneos habían transformado casi en una evidencia incuestionable. De igual modo, Bialet Massé se niega a reproducir en Argentina, acríticamente y sin mediación reflexiva, los discursos y tesis sobre higiene, legislación y medicina laboral, hegemónicos entre los intelectuales europeos. En cambio, destaca la necesidad de comenzar a desenvolver, en Argentina, un pensamiento científico y una legislación propia, que no se limite a repetir e imitar "malamente" las leyes y las certezas establecidas por los intelectuales en Europa. ${ }^{19}$

Bialet Massé se atreve también a otra cosa. Su Informe trae un poco de aire fresco en esa monotonía conservadora y fuertemente racista que caracterizaba a la elite intelectual argentina. Por ese motivo, en este artículo me propongo analizar algunas particularidades significativas que distinguen a este médico catalán, que a los 58 años y por un período de cuatro meses recorrió los lugares más inhóspitos y alejados de Argentina, para intentar entender el día a día y las condiciones de vida de los trabajadores rurales y urbanos argentinos, sus necesidades, padecimientos, sufrimientos y sueños.

Ese discurso contrasta claramente con la forma como el mundo del trabajo y el cotidiano de los trabajadores argentinos, fundamentalmente de aquellos que habitaban en el interior del país, era visto por otros intelectuales que publicaron sus estudios exactamente en ese mismo momento histórico. Sin embargo, Bialet Massé nunca consiguió alcanzar el mismo nivel de reconocimiento académico, ni el prestigio científico conquistado por otros pensadores de la época, como fue el caso de José Ingenieros, uno de los intelectuales de inicios de fines del siglo XIX e inicios del siglo XX, más valorizados de la tradición argentina. Tal es así que aún en 1994, Eduardo Zimmerman puede referirse a él en estos términos: "José Ingenieros en cierto modo encarnaba la fusión del progresismo político y la vanguardia intelectual y científica que impulsó al reformismo social de la época". ${ }^{20}$

Tenemos así dos miradas sobre la pobreza que coexisten en un mismo momento histórico (1903-1904) y en un mismo lugar geográfico. La de José

8 BIALET MASSÉ. Informe sobre el estado de la clase obrera, p. 15.

19 BIALET MASSÉ. Informe sobre el estado de la clase obrera, p. 19.

20 ZIMMERMANN, Eduardo. Los Liberales reformistas. Buenos Aires: Ed. Suadamericana,1994, p. 112. 
Ingenieros, que contó con el reconocimiento de la intelectualidad argentina, y la de Bialet Massé, que permaneció prácticamente desconocida por casi cuarenta años. La tesis de doctorado de José Ingenieros La simulación de la locura, fue publicada en 1903, exactamente un año antes que apareciera el Informe de Bialet Massé.

En el año 1906, Ingenieros presentará orgullosamente en Francia un texto denominado La legislation du travail dans la Republique Argentine ${ }^{21}$ referido a la Ley Gonzales que, sin embargo, solo será discutida y aprobada muchos años más tarde. Tal parece ser que, como afirma Trimboli:

\begin{abstract}
tan suficiente era el envanecimiento de esa elite que, para un intelectual incorporado a ella a pesar de su origen inmigrante y de su magra fortuna - me refiero a José Ingenieros - el mero hecho de que ese código de trabajo estuviera redactado le alcanzaba para jactarse, en reuniones internacionales laboristas, de la sapiencia del Estado que él representaba. No importaba que la mayor parte de esas leyes fueran sancionadas recién durante el primer gobierno peronista. ${ }^{22}$
\end{abstract}

Sin embargo, aún cuando Ingenieros reconozca el valor de algunas de las propuestas de legislación laboral realizadas por Bialet Massé para el proyecto de Ley de Joaquin $V$ Gonzales, me detendré aquí a analizar las significativas diferencias que existen entre ambos.

Particularmente, serán analizadas las tesis defendidas por Ingenieros en algunos textos que considero claves para entender el modo como abordaba las cuestiones vinculadas a la oposición trabajo-ociosidad. Una oposición que, para Ingenieros, estaba vinculada al modo como era tematizada la cuestión racial. Los textos que serán aquí privilegiados son: La simulación de la locura, publicada en 1903, La formación de la raza Argentina, publicada algunos años más tarde, en 1915, y un artículo denominado La pereza latinoamericana, publicado en 1903, que más tarde formará parte del libro Sociología Argentina.

Específicamente, pretendo analizar el modo como Juan Bialet Massé y José Ingenieros piensan las cuestiones referidas a la fatiga, al descanso, al ocio y a la pereza. Estos temas, están directamente vinculados a la posición que ellos adoptan frente a cuestiones biopolíticas tales como los procesos migratorios, la cuestión racial o el papel social, autónomo o subordinado, que le cabe asumir a Argentina frente a países como Inglaterra, Francia o Estados Unidos.

Tomaré como punto de partida para este análisis el libro de Anson Rabinbach Human Motor. ${ }^{23}$ Observando la tesis que articula el libro de Rabinbach podemos afirmar que José Ingenieros y Bialet Massé se sitúan en espacios teóricos diferentes y antagónicos, en polos opuestos en lo que se refiere a la relación cuerpo-trabajo-pobreza. Todo lleva a pensar que estamos hablando aquí de dos autores que produjeron sus estudios separados por décadas y no simplemente, como efectivamente ocurrió, por algunos pocos meses.

Así, partiendo de la perspectiva de análisis abierta por Rabinbach, podemos afirmar que el Informe de Bialet Massé inaugura una ruptura significativa en el modo de tematizar el mundo del trabajo en Argentina. Casi veinte años más tarde, la perspectiva de análisis propuesta por Bialet Massé reaparecerá en Argentina con el texto de Alfredo Palacios denominado La Fatiga y sus proyecciones sociales, ${ }^{24}$

21 INGENIEROS, José. La legislation du travail dans la Republique Argentine. In: Obras Completas. Buenos Aires: Ed. Mar Océano, 1961.

22 TRIMBOLI. Mil novecientos cuatro, p. 8.

23 RABINBACH. The human motor.

24 PALACIOS, Alfredo (1922). La Fatiga y sus proyecciones sociales. Buenos Aires: Editorial Claridad, 1944. 
publicado en 1922. Es sorprendente constatar las semejanzas existentes entre el modo como Palacios aborda las condiciones de vida y trabajo de la clase obrera con los estudios que ye habían sido realizados, veinte años antes, por Bialet Massé.

Podemos afirmar que hasta el Informe de Bialét Massé, el objeto de preocupación que concentraba la atención de los médicos y reformadores sociales era, fundamentalmente, el problema representado por el ocio y la pereza, motivo por el cual es posible afirmar que, en ese momento, ocurrió una verdadera ruptura con la tradición precedente, obcecada por la pereza. Rabinbach define este momento de transición, diciendo que:

Hacia el final del siglo XIX, la pereza comenzó a declinar como el modo predominante de conceptualizar la resistencia al trabajo. Las razones de esta declinación pueden ser enumeradas: la vieja proscripción cristiana de la pereza fue perdiendo valor para los trabajadores urbanos y para los industriales; más que una disciplina y una dirección impuestas desde el exterior, la tecnología del sistema fabril requería un cuerpo internamente regulado y al servicio de la máquina. Consecuentemente, el ideal del trabajador guiado por la autoridad espiritual o por la vigilancia y el control directo, dio lugar a la imagen de un cuerpo dirigido por sus propios mecanismos internos: el motor humano. Casi simultáneamente, fatiga y energía emergieron como un marco conceptual más moderno para expresar las relaciones entre cuerpo y trabajo. Así, el concepto de trabajo sufrió una transformación crucial: la fatiga, y no la pereza, era el principal descontento del trabajo industrial. ${ }^{25}$

Sin embargo, la preocupación moralizadora por la pereza, que fue el eje prioritario de discusión del saber médico referido al mundo del trabajo en la primera mitad del siglo XIX, continuó siendo el tema central de preocupación para muchos intelectuales argentinos, entre ellos para José Ingenieros, aún en el año 1903.

$Y$ es en ese mismo momento que Bialet Massé inaugura, en Argentina, un nuevo modo de entender la fuerza de trabajo y el cuerpo del trabajador, a partir de la temática de la "fatiga". Aborda el sufrimiento de los trabajadores desde un marco epistemológico libre de las clásicas oposiciones entre el trabajo que ennoblece y la pereza que enferma. El cuerpo de los trabajadores pasa a ser analizado por nuevas categorías tales como: el gasto de energía, tiempo de trabajo, explotación, accidentes, reducción de esfuerzos excesivos, alimentación adecuada, tiempo de descanso y placer. Allí, quedaba poco espacio para las viejas explicaciones centradas en la ociosidad, repetidas desde la Edad Media y que se mantenían intactas en el discurso de Ingenieros. Es verdad que, como afirma Rabinbach:

Ciertamente, los escritores moralizadores continuaron condenando la pereza y escribiendo sobre las virtudes del trabajo, pero los efectos destructivos de la irregularidad y el exceso de trabajo fueron nuevos y poderosos temas en un creciente número de tratados concernientes al trabajo industrial. ${ }^{26}$

En ese contexto es preciso situar los trabajos que Ingenieros dedica al mundo de la pobreza que estará, para él, directamente vinculada con la ociosidad. Ya sea por la relación que establece entre alcoholismo y criminalidad, por sus referencias a la idea de degeneración, o por la jerarquización de razas que adopta, la cuestión pereza-raza parece ser un eje articulador de sus trabajos.

25 RABINBACH. The human motor, p. 35 .

26 RABINBACH. The human motor, p. 36. 


\section{La ofensiva contra la pereza}

La obra de José Ingenieros se inscribe en un momento histórico clave para la constitución de Argentina como Estado-Nación. Forma parte de un grupo de intelectuales positivistas que desde los años 1880 hasta $1910^{27} \mathrm{crearon}$ discursos y estrategias tendientes al proceso de modernización del país. Esta circunstancia imponía nuevos desafíos destinados a la gestión biopolítica de las multitudes argentinas. Surgieron entonces, grandes debates en torno a fenómenos tales como la reorganización urbana, la educación infantil, la puericultura, el mundo del trabajo. También, en ese momento, aparece la necesidad de definir nuevas formas de administrar los problemas que surgían como efecto de ese proceso modernizador, tales como: crimen, locura, inmigración, organización del trabajo, sin dejar de lado los problemas referidos a la cuestión racial. En este marco debemos situar a José Ingenieros, cuyos estudios no solo estaban dedicados a la medicina y psiquiatría, sino también a la sociología, a la psicología y, fundamentalmente, al campo naciente de la criminología. ${ }^{28}$

En esa diversidad de temas, asuntos y problemas que tanto le preocupaban, podemos identificar ciertas cuestiones, que se reiteran en sus escritos, vinculadas a las clases populares. Frente al poder moralizador y normalizador del trabajo, Ingenieros sitúa la amenaza patológica de la pereza, frecuentemente vinculada con la cuestión racial.

Estos temas ya aparecen en su primer texto, La simulación de la locura. Inicialmente este escrito fue presentado bajo la forma de una Tesis para obtener el título de médico, y fue defendida en el año 1900. Más tarde, en 1903, este trabajo será publicado en forma de libro agregándole un capítulo inicial denominado La simulación en la lucha por la vida. Por esta obra, la Academia de Medicina de Buenos Aires le otorgó la medalla de oro destinada a premiar la mejor obra científica argentina. De tal modo que, como afirma Cristina Fernandez, ${ }^{29}$ La simulación de la locura cimenta la fama de Ingenieros como el más prestigioso alienista, sociólogo y criminalista argentino de su época. ${ }^{30}$

Para Ingenieros cada acto individual de simulación humana, sea consciente o inconsciente, voluntario o accidental, debe ser analizado como una estrategia psicológica utilizada para adaptarse a las condiciones y restricciones impuestas por el medio. Este recurso no es exclusivo del mundo de los delincuentes y marginales, al contrario, puede identificarse en los más variados ámbitos de la acción humana.

Ingenieros utilizará argumentos semejantes para referirse a la simulación en la lucha por la vida en el mundo del trabajo. Miembros de diversas profesiones, particularmente los funcionarios públicos y burócratas, harán de la simulación su verdadera profesión. Así, aquellos que no quieren trabajar simularán la fatiga

27 TERÁN. Positivismo y nación, p. 14, analiza ese momento histórico de la Argentina de fines del siglo XIX e inicios del siglo XX, afirmando que: "En el área del ensayo positivista argentino, lo más significativo transcurre centralmente en las obras de José Ramos Mejía, Agustín Alvarez, Carlos Octavio Bunge y José Ingenieros".

28 José Ingenieros sucedió a Ramos Mejía en la cátedra de Neuropatología (entonces llamada Patología nerviosa) en la Universidad de Buenos Aires. En el año 1904 Ramos Mejía publicará Los simuladores de talento, retomando algunas de las ideas expresadas por Ingenieros en "La simulación de la locura".

29 FERNANDEZ. “¿Teorías científicas fuera de lugar?”.

30 Sobre la influencia de los estudios de José Ingenieros en el desarrollo del positivismo argentino ver, entre otros BIAGINI. El movimiento positivista argentino; VERMEREN y VILLAVICENCIO. "Positivismo y ciudadanía”; STAGNARO. "Evolución y Situación de la Historiografía de la psiquiatría Argentina”. 
constante y el agotamiento, pues, para él existen, “legiones enteras de parásitos y serviles que viven simulando trabajar". ${ }^{31}$

Dentro de este universo de simulaciones deben ser diferenciados los casos de simulación en general, allí donde aparecen casos de fraude, mentira y ocultamiento, de un tipo especial que es la simulación de estados patológicos. Ingenieros presenta tres tipos de simulación de patologías: (1) los que simulan una enfermedad para liberarse del servicio militar; (2) la simulación de los falsos mendigos para favorecerse de la beneficencia; y (3) la simulación de la locura en general y por los delincuentes en particular.

Refiriéndose al segundo tipo de simulación hablará de parasitismo social, de grandes grupos de mendigos que han hecho de la mendicancia una verdadera profesión, beneficiándose de la solidaridad de los semejantes, muchas veces, haciendo verdaderas fortunas. Relata el caso de un famoso club de mendigos existente en la ciudad de Chicago; "una comitiva de sujetos sanísimos y alegres que comían, bebían, jugaban, fumaban y poseían una biblioteca de filósofos antiguos para recrearse en sus ratos de ocio. Todos ellos, durante el día, simulaban ser cojos, ciegos, mudos o idiotas". 32

Ingenieros reitera, de ese modo, un tópico extremamente difundido a lo largo del siglo XIX por filántropos y asociaciones de asistencia, presente también en la literatura y en el cine. Pensemos en los relatos de Emil Zola ${ }^{33}$ y Victor Hugo, o posteriormente, en filmes como la película argentina "Dios se lo pague". ${ }^{34}$ De formas diferentes, esos discursos se referían a un fenómeno que atormentaba a las nacientes estructuras de protección social, surgidas como respuesta a los conflictos sindicales y a las luchas políticas que ocurrieron en el siglo XIX en Europa y, más tarde, en América Latina. Lo aparecía como un problema, que obstaculizaba la creación y aplicación de leyes protección social a los trabajadores, era la dificultad para diferenciar claramente la pobreza digna de la pobreza considerada indigna. Esto es, la dificultad en establecer una clara distinción entre la población trabajadora, merecedora de ayuda, de aquellos que no la merecían. 35

Ingenieros continuará repitiendo esa forma de pensar que caracterizaba a los estudios referidos al trabajo, en la primera mitad del siglo XIX. Para esos estudios, "tanto literal como figurativamente, la pereza era el pecado original en contra de la industria [... ]. Ya en 1807, Napoleón había dado el tono cuando concluyó cuanto más trabaje el pueblo, menos vicios él tendrá". ${ }^{36}$

En este contexto las referencias al evolucionismo, al darwinismo y a la lucha por la vida, considerados por Ingenieros como argumentos necesarios para construir una teoría científica sobre la simulación, resultaban de gran utilidad para defender argumentos políticamente conservadores. ${ }^{37}$ La analogía trazada entre el mundo animal y humano en el primer capítulo de La Simulación de la locura, retorna ahora como forma de justificar la exclusión de la solidaridad social a los no trabajadores, un grupo integrado por diferentes tipos de degenerados. Así,

31 INGENIEROS. La simulación de la locura, p. 58.

32 INGENIEROS. La simulación de la locura, p. 100.

33 ZOLA, Émile. L'assommoire. Paris: Ed. G. Charpentier, 1877.

34 AMADORI, Luis Cesar (Director). Dios se lo pague. Buenos Aires: Argentina Sono Film S.A.C.I. 1948.

35 HIMMELFARB, Gertrud. La idea de Pobreza. México: Fondo de Cultura Económica, 1988.

36 RABINBACH. The human motor, p. 29.

37 Algo semejante ocurrirá com la Escuela Jurídica Positiva defendida por Enrico Ferri. Al respecto ver: GALFIORE, María Carla. "La sociología criminal de Enrico Ferri: entre el socialismo y la intervención disciplinaria”. VII JORNADAS DE SOCIOLOGÍA DE LA UNIVERSIDAD NACIONAL DE LA PLATA, La Plata, 2012. Sitio web: http://jornadassociologia.fahce.unlp.edu.ar. 
refiriéndose a las desventajas que puede llegar a tener la solidaridad social, que inspiran los necesitados y los simuladores, afirma:

\begin{abstract}
Mientras multitudes laboriosas y fecundas carecen de lo necesario, duele ver que los manicomios, las cárceles, los asilos contribuyan a la cómoda holgazanería de seres improductivos, cuando no perjudiciales. El eterno problema de la lucha contra el parasitismo social de los degenerados, frente a la justa protección de las clases trabajadoras. Sergi en Las degeneraciones humanas, ha dedicado un bello estudio a la supervivencia de los débiles e inferiores. ${ }^{38}$
\end{abstract}

Por ese motivo, para Ingenieros, la función social de la medicina debería estar orientada con fines selectivos para la defensa de la especie humana, que en tanto especie biológica, debería "tender a la conservación de los caracteres superiores y a la extinción de los incurables y degenerados". ${ }^{39}$ De ese modo podrán ser evitados dos males sociales: el desperdicio de fuerzas y recursos destinados a la solidaridad con los inferiores, que conduce al parasitismo social, y la transmisión hereditaria de caracteres degenerativos, considerados perjudiciales para la evolución de la especie.

Para Ingenieros, la forma de responder al flagelo social que representa la simulación de enfermedades para favorecerse de la beneficencia, será la profilaxis. Deben ser creadas reformas laborales que hagan del trabajo una obligación agradable para todos y no una desagradable imposición, o "un yugo penoso para algunos"..$^{40}$ En ese sentido, defiende intervenciones sociales y eugénicas capaces de establecer una partición en el mundo social entre, el mundo de los hombres laboriosos merecedores de la beneficencia "tendiendo a la conservación de los caracteres superiores de la especie", y ese otro mundo, el de los débiles a los que toda asistencia debería ser negada tendiendo a su extinción. ${ }^{41}$ Se reitera así, en el discurso de un intelectual socialista argentino, esa antigua letanía por la cual, "desde el Siglo XIII, hasta la mitad del Siglo XIX, escritores cristianos, predicadores, y moralistas de la clase media, estigmatizaron a la pereza como la némesis de una vida ordenada y de la disciplina del trabajo". ${ }^{42}$ Un estigma indisociable de la reiterada referencia a la asociación entre "clases pobres" y "clases peligrosas". ${ }^{43}$

\title{
Sobre la fatiga y los sufrimientos evitables
}

Solo un año más tarde, en 1904, Bialet Massé presentará una visión del mundo de los trabajadores absolutamente diferente. El eje ya no estará dado por el tema de la pereza, que tanto había preocupado a los moralizadores, ahora se trata de substituir esos argumentos morales y punitivos por un conjunto de discursos y saberes que incluyen la fisiología, la nutrición y la higiene. Es a partir de ese conjunto de saberes muy disimiles, aún en pleno proceso de construcción, que Bialet Massé se sitúa para realizar sus observaciones, mediciones y cálculos. ${ }^{44}$ Todo ese instrumental será esencial para construir argumentos críticos y bien fundados

38 INGENIEROS. La simulación de la locura, p. 94.

39 INGENIEROS. La simulación de la locura.

40 INGENIEROS. La simulación de la locura, p.100.

41 INGENIEROS. La simulación de la locura, p. 99.

42 RABINBACH. The human motor, p. 26.

43 CHEVALIER, Luis. Classes laborieuses et classes dangereuses. Paris: Ed. Pluriel, 1978.

44 FLOYD, W. F. y WELFORD, A. T. Fatiga y trabajo. Buenos Aires: Eudeba, 1968; CORIAT, Benjamín. El Taller y el cronómetro. México: Siglo XXI, 1982. 
destinados a desnaturalizar esos discursos que se limitaban a hablar de la pereza de los nativos.

Se trataba de realizar, en Argentina, observando sus peculiaridades y problemas específicos, estudios semejantes a aquellos que, en ese momento eran realizados por médicos interesados en el mundo del trabajo. Las investigaciones de Mosso ${ }^{45}$ y de Tissié ${ }^{46}$, de los cuales Bialet Massé debe haber tenido conocimiento, no son citados ni una única vez a lolargo de su Informe ${ }^{47}$. Sin embargo son constantes las referencias de Bialet Massé a los conocimientos entonces aceptados, provenientes del campo de la fisiología y la mecánica, así como también es recurrente el uso a instrumentos de medición de la fatiga. Como afirma Rabinbach:

Como resultado del desarrollo en la Fisiología de fines del siglo XIX, especialmente la mecánica del movimiento corporal y el problema del calor fisiológico, los fisiólogos diseñaron instrumentos (el ergógrafo, el estesiómetro) para registrar cambios mínimos en el curso objetivo de la fatiga durante cualquier ocupación o tarea. A fines de la última década del siglo, científicos de Francia, Italia y Alemania investigaron ampliamente diversos aspectos de la fatiga tales como desempeño laboral, fatiga mental, dieta y nutrición de los trabajadores. Estudios extensos, que se centraban en aspectos legales, estadísticos y médicos de la fatiga fueron usados para calcular y conservar el capital productivo de la nación. ${ }^{48}$

Así, teniendo como marco de referencia esos conocimientos, Bialet Massé realizará su trabajo de observación, recorriendo las diferentes regiones de Argentina: la Rioja, Jujuy, Córdoba, Santa Fe, Chaco, Tucumán, San Luis, Mendoza y San Juan. Aquí ya no se trataba de demarcar lo moral y lo inmoral, lo normal y lo patológico a partir de la clásica y discutible oposición entre trabajo y pereza. Para poder entender el real sufrimiento de los trabajadores, para poder crear condiciones de trabajo dignas, era necesario construir una nueva forma de conceptualizar la relación cuerpo-trabajo. Debía negarse a naturalizar las condiciones de explotación inhumana a las cuales estaban sometidos los trabajadores, particularmente, los trabajadores del interior del país, así como las condiciones de efectiva esclavitud a la que estaban sometidos los trabajadores indígenas. Bialet Massé, parte de una afirmación que hoy podemos leer en clave foucaultiana, considera que es necesario problematizar el presente cuestionando aquello que se supone evidente, natural y necesario, pues:

No se curan las llagas ocultándolas o velándolas a la vista del cirujano, por un pudor mal entendido: es preciso, por el contrario, presentarlas en toda su desnudez, en su verdad, manifestando sus antecedentes con toda sinceridad, para aplicarles el remedio conveniente. ${ }^{49}$

Resultaba necesario dirigir a los trabajadores una mirada capaz de integrar las nuevas discusiones y estudios que, en ese momento, concentraban la atención de los médicos del trabajo y analizar las legislaciones laborales internacionales. Estos estudios giraban en torno a un nuevo objeto de preocupación, el problema de la "fatiga". Para realizar esas investigaciones en Argentina, debían ser analizados

45 MOSSO, Angelo. La fatiga. Madrid: Ed. Jarro, 1891.

46 TISSIIÉ, Philippe. La fatiga y el adiesteamiento físico. Madrid: Imprenta Rojas, 1897.

47 A diferencia de lo que afirma Diego Roldán em: “Discursos alrededor del cuerpo".

48 RABINBACH. The human motor, p. 23.

49 BIALET MASSÉ. Informe sobre el estado de la clase obrera, p. 14. 
en su especificidad, los diferentes tipos de trabajo y las diferentes actividades industriales. Bialet Massé estudia la industria de transporte, el trabajo a domicilio, la industria azucarera, el trabajo agrícola, la minería, la industria del calzado, la carga y descarga de buques, las panaderías, el planchado y el lavado, entre otros. A pesar de su extensión, este breve trecho extraído del Informe de Bialet Massé, puede darnos una muestra de la importancia social y médica atribuida al problema de la fatiga, que reaparecerá en diversos momentos como eje articulador de su Informe:

En las cumbres del Famatina he visto al apire cargado con 60 kilogramos, y más, deslizarse por las galerías de las minas, corriendo riesgos de todo género, en una atmósfera de la mitad de la presión normal; he visto en la ciudad de la Rioja al obrero, ganando sólo 80 centavos, metido en la zanja estrecha de una cañería de aguas corrientes, aguantando en sus espaldas un calor de $57^{\circ}$, a las dos de la tarde; he visto a la lavandera de Goya lavar una docena de ropa a 30 centavos, bajo un sol abrasador; he visto en todo el Interior la explotación inicua del vale de proveeduría; he visto en el Chaco explotar al indio como bestia que no cuesta dinero, y he podido comprobar, por mí mismo, los efectos de la ración insuficiente en la debilitación del sujeto..$^{50}$

Para este autor, el trabajo ha dejado de ser eminentemente moral, ha dejado de ser ese instrumento de corrección con el que soñaban los moralistas del siglo XIX. El trabajo ha pasado a ser una cuestión que es, al mismo tiempo, social, política y técnica. El cuerpo de quien trabaja también parece haber cambiado de estatuto, dejando de ser un autómata cartesiano, una maquina auto-regulable, para pasar a ser un "motor delicado que se debe conservar cuidadosamente" 51 . Ese cuerpo, ya no se rige de acuerdo a las leyes de la mecánica sino que, respondiendo a los principios de la termodinámica, tiende a agotarse.

Finalmente, un cambio profundo en la percepción del trabajo y del cuerpo laborioso quedó plasmada en una metáfora simple: el frecuentemente invocado motor humano, una imagen impactante que ilumina una afinidad subyacente entre Fisiología y Tecnología. Una imagen originada en una igualmente nueva percepción del universo como dinamo industrial, o motor, que fue el logro de la teoría termodinámica surgida en el siglo XIX.52

El Informe de Bialet Massé puede ser leído como una gran estrategia para contornear los peligros de la fatiga, para controlar la explotación deshumana que era regla general en la mayor parte del territorio Argentino. Y para eso, ya no tendrá como referencia a la estadística, método privilegiado para establecer grados de patología social y de criminalidad, sino a la fisiología y su aplicación en la nueva ciencia de la fatiga. Ese saber permitirá definir, de modo inequívoco, las horas de descanso y las de trabajo, fijar con precisión el contenido y la cantidad de ración diaria que un trabajador debe consumir para rendir a un máximo sin fatigarse, regular los tiempos y las cadencias de las distintas tareas.

Lejos de las preocupaciones de los gerentes decimonónicos europeos, como Andrew Ure en Inglaterra o Denis Poulot ${ }^{53}$ en Francia, obsesionados por los peligros del poder que otorga el conocimiento de un oficio a los más calificados,

50 BIALET MASSÉ. Informe sobre el estado de la clase obrera, p. 12.

51 BIALET MASSÉ. Informe sobre el estado de la clase obrera, p. 731.

52 RABINBACH. The human motor, p. 24.

53 POULOT, Denis. Le sublime. Paris: Ed. Maspero, 1980. 
el problema de Bialet Massé parece ser el reconocimiento de una ignorancia generalizada entre los patrones y los encargados de la organización del trabajo en los diferentes oficios. Así, para Bialet Massé:

La primera gran afirmación que creo poder hacer es que: he encontrado en la república una ignorancia técnica asombrosa, más en los patrones que en los obreros. He visto maquinistas que no saben cómo actúa el vapor, carpinteros que no saben cómo usar la garlopa, electricistas que no saben que es la electricidad [... ] pero es mayor, si cabe, la ignorancia patronal. ${ }^{54}$

Y será extrañamente en ese mismo marco discursivo que encontraremos referencias a la pereza. Es que los perezosos que más le preocupan a Bialet Massé no son los indígenas, ni los mestizos, sino aquellos que él llamará "los de arriba". Así, refiriéndose a un problema que encuentra recurrentemente en la provincia de Córdoba, donde los trabajadores deben enfrentarse con la amenaza permanente de la desocupación, o de lo que hoy denominaríamos precariedad laboral, Massé se referirá a la falta de previsión y de visión de futuro de industriales de corta mira preocupados con su ganancia inmediata y temerosos de arriesgar su capital:

En el presente merecemos azotes por pereza, látigo por indolentes y palo por disipación de inteligencias y energías. Los de arriba se lo achacan al pueblo; es que no se ven ni se examinan; y los de abajo se van (de Córdoba), en busca de algo mejor, fuera de casa, arrostrando los azares de la emigración, los aprendizajes y sufrimientos, llegan a desplegar energías que ni sospechaban tener en el ambiente de su tierra. Se van a la Capital Federal, aumentando la monstruosidad cefálica; a Santa Fe, trillando, estibando, cortando madera. ${ }^{55}$

De ese modo, el informe de Bialet Massé permite tematizar a las "multitudes argentinas" desde un nuevo espacio discursivo. Hasta allí las cuestiones referidas a la inmigración y a la capacidad laboral del trabajador nativo parecían reproducir siempre una misma letanía: la pereza del criollo. Las "biopolíticas de la población" llevaban por entonces la marca de la eugenesia: la raza y la herencia eran los problemas a resolver. El Informe de Bialet Massé rompe con esos discursos que insistían en la natural tendencia del trabajador nativo a la ociosidad.

Mientras la costurera de Tucumán, de la Rioja y Córdoba; mientras el obrero de la Rioja y Catamarca, de Corrientes y Santiago sienten los efectos de la ración insuficiente, del hambre lento, que degenera la raza, se ostentan rodeos por decenas de millares y hay vacas y ovejas por millones. No se diga que por pereza, por vicio, no; el que padece de esa inanición lenta, de esa vejez prematura, de esa muerte anticipada e inmerecida, es el obrero que arranca el oro de las entrañas del Famatina; es el obrero que hace y mueve ferrocarriles; es el obrero que cuida el ganado que se exporta; es la mujer laboriosa y abnegada que lava y plancha y cose para dar un pedazo de pan a sus hijos; no es la resaca del vicio de las grandes ciudades; es la víctima del error y de la codicia, del prejuicio y de la ignorancia. ${ }^{56}$

Contradiciendo los prejuicios y mitos defendidos por autores como Ingenieros, Bialet Massé se referirá a la excelencia del criollo y del mestizo como

54 BIALET MASSÉ. Informe sobre el estado de la clase obrera, p. 19.

55 BIALET MASSÉ. Informe sobre el estado de la clase obrera, p. 256.

56 BIALET MASSÉ. Informe sobre el estado de la clase obrera, p. 490. 
artesanos y peones. Dirá que para que esa excelencia se manifieste en plenitud, resultaba necesario adoptar medidas jurídicas capaces de penalizar los abusos a los que los trabajadores nativos estaban sometidos, cambiar sus condiciones de vida y modificar los contratos de trabajo. Para que estas reformas pudieran ser aceptadas por el poder político y económico, era necesario realizar cálculos y mediciones, obtener datos que, de modo objetivo, pudieran mostrar que la fatiga es un fenómeno fisiológico que nos afecta a todos, pero muy particularmente a los trabajadores sometidos a esfuerzos repetidos por horas, cuya alimentación es deficiente.

El trabajo, como gasto de energía, queda así desvinculado de cualquier valoración moral y de toda vinculación con el viejo mito de la pereza. Esos cálculos referidos a la fuerza de los trabajadores, realizados con en auxilio de dinamómetros, o los estudios sobre la cantidad de calorías ingeridas y la cantidad de calorías necesarias, así como las mediciones de altura y temperatura del ambiente donde se realizaban las tareas, permitían establecer las necesidades de nutrición y descanso, las pausas, la importancia de limitar la exigencia de fuerza física empleada en las tareas. Propone medidas simples destinadas a restituir el respeto a la dignidad y a la individualidad, reconociendo las dificultades existentes en cada trabajo y en cada medio ambiente específico. Concluirá, entre otras cosas, que la alimentación del trabajador debe ser suculenta y abundante como aquella que se encuentra en la mesa de los ricos, pues "el rico no tiene más gasto de calorías que el pobre, sino menos". 57

Aunque estos estudios se inscriben en el marco de las investigaciones que, en ese momento, eran desarrolladas por una medicina de trabajo interesada por el fenómeno de la fatiga, la reposición y gasto de energía o los accidentes de trabajo, Bialet Massé se niega a repetir acríticamente esas teorías. Considera que deben realizarse cálculos, entrevistas, observaciones para entender las peculiaridades que presenta el problema de la fatiga en cada tarea y en cada región del país.

Este breve desplazamiento que va de la preocupación por la pereza al estudio de la fatiga, pudo haber tenido importantes efectos jurídicos que el proyecto del código del trabajo de Joaquín V. González pretendió, sin éxito introducir. Allí se enuncia por primera vez desde el ejecutivo, un proyecto que en 14 títulos y 466 artículos pretendía racionalizar desde un punto de vista jurídico el confuso mundo del trabajo. Cuestiones como asistencia médica, accidentes, pagamento de salarios, y la necesidad de imponer un límite de 8 horas al trabajo y el descanso semanal, eran por primera vez problematizadas. ${ }^{58}$

Como vemos, el informe de Bialet Massé parece ocupar un espacio estratégico en la historia de las ciencias sociales argentinas. Su problematización comporta un interés que excede el ámbito del análisis histórico. Permite replantear la historia de esos saberes que, en las últimas décadas del siglo XIX y los primeros años del siglo XX, se propusieron racionalizar el mundo de los trabajadores sin que esto signifique necesariamente, como ocurrirá con la gestión

57 BIALET MASSÉ. Informe sobre el estado de la clase obrera, p. 290.

58 De acuerdo a ROLDAN. “Discursos alrededor del cuerpo", p. 654. “El Informe de Bialet Massé se justificaba por la ausencia de intereses políticos (subjetivos) y por la validez universal de sus premisas asentadas en el discurso científico". Al mismo tiempo afirma que Bialet Massé sería un defensor de las ideas que vinculan pereza e inacción con vicios morales. Considero, al contrario, que el Informe presenta una clara y definida perspectiva política en defensa de los trabajadores y que, por otra parte, inicia un nuevo tipo de discurso que se opone a la clásica condena moral a la pereza. Aún cuando puedan encontrarse algunas referencias aisladas donde repite la clásica oposición: trabajo/virtud-pereza/vicio, es posible afirmar, como intento mostrar en este escrito, que los argumentos defendidos por Bialet Massé se sitúan en un nuevo espacio discursivo. 
taylorista, una desconsideración de las condiciones de vida, de los pesares o de los sufrimientos presentes en el mundo del trabajo. Las cuestiones que le preocupan a Bialet Massé son las mismas que formaban parte de las clásicas luchas laborales, recuperando las reivindicaciones presentes en las pautas de los movimientos obreros y en la pauta de la mayor parte de las huelgas entonces realizadas. Ocurre que, de acuerdo a Rabinbach

La fatiga definió tanto los límites del cuerpo trabajador como el punto del cual la sociedad no podía huir sin poner en peligro su propia capacidad futura de trabajo. Por esta razón, la fatiga también devino el concepto y el medio a través del cual el cuerpo del trabajador podía ser mejor entendido y empleado. El cuerpo sin fatiga era el ideal, no sólo de la burguesía industrial, sino también del movimiento obrero, el cual, aunque de modo diferente, también imaginaba un punto de rendimiento productivo máximo y un mínimo de cansancio, como siendo el sumum bonum de la sociedad moderna. ${ }^{59}$

Debemos destacar aquí una de las mayores contradicciones del estudio de Bialet Massé destacada por Recalde. ${ }^{60}$ Ciertamente, mantiene una posición ambigua en relación a las huelgas y presenta una propuesta de reglamentación de las mismas que hoy sería inadmisible. Sin embargo, es de otro modo que se sitúa en el momento concreto en que se deflagra una huelga en Córdoba en una industria de calzados que imponía condiciones deshumanas a sus obreros. El trabajo se extendía por 11 o 12 horas, inclusive para muchas mujeres que debían trabajar de pie. Bialet Massé intenta conversar con el propietario del establecimiento sin ningún éxito, mostrándose completamente refractario a sus demostraciones sobre las ventajas de reducir el trabajo a 8 horas diarias, una resistencia patronal que inevitablemente conduciría a una huelga. Massé dirá que esa huelga:

no podía dejar de producirse. Por paciente y manso que sea el trabajador, llega el momento en que la naturaleza habla y se subleva. La huelga ha empezado por los cortadores, a los que se les exigen doce y más horas, a pretexto de que tienen que preparar el trabajo para el día siguiente, para que no se interrumpa. Hay en esta industria algo que extrañará a V. E.: es el cobro de dos centavos por el uso de la letrina; y iqué letrinas! se pueden pagar cinco por no usarlas. ${ }^{61}$

El Informe, independientemente de estas y otras contradicciones, consigue trazar un cuadro dramático de los sufrimientos cotidianos, del abandono y de la desidia con que fueron tratados los trabajadores argentinos a inicios del siglo XX. Un cuadro que, como sabemos, permanecerá inalterado por más de cuarenta años. Sin embargo, aún hoy, y pese a la importancia que un análisis detallado de este texto podría representar tanto para la historia del trabajo como para la sociología laboral, son indirectas e insuficientes las referencias teóricas o los estudios dedicados a este Informe, exceptuando algunos pocos escritos, entre los que destacamos los trabajos de Trimboli y de Roldán ya aquí mencionados.

59 RABINBACH. The human motor, p. 23.

60 RECALDE. "Prólogo".

61 BIALET MASSÉ. Informe sobre el estado de la clase obrera, p. 320. 


\title{
Pesimismo climático y cuestión racial
}

De lo dicho hasta aquí podemos concluir que Bialet Massé y José Ingenieros representan dos modos diferentes de pensar el cuerpo del trabajador, dos perspectivas claramente opuestas que, sin embargo, convivieron en el mismo momento histórico. Pero estas diferencias no se sitúan exclusivamente en el hecho que la pereza ocupe en el discurso de Ingenieros un lugar central, mientras que en Bialet Massé la centralidad estará dada por la preocupación con la fatiga. Ocurre que esas cuestiones no se refieren a los trabajadores como una multitud homogénea. Por el contrario, estos dos modos de abordar el cuerpo de quien trabaja determinará la manera como cada uno de estos autores se sitúa frente a uno de los problemas centrales de la construcción de la identidad argentina: la cuestión racial. Ingenieros y Bialet Massé abordan de una manera completamente diferente el papel que le cabe ocupar a los nativos, a los pueblos indígenas, a los criollos, a los mestizos y a los inmigrantes europeos en la naciente sociedad argentina.

Es necesario destacar una segunda oposición entre Ingenieros y Bialet Massé, que está directamente vinculada con la oposición pereza-fatiga. En este caso, la oposición no se refiere a individuos o grupos profesionales, sino a las multitudes argentinas, esto es, a los diferentes modos de abordar las poblaciones, sean locales o nativas y las oleadas migratorias.

En el caso de Ingenieros, la pereza será la principal característica atribuida atribuye a los criollos, mestizos y nativos, una población a la que desprecia y a la que considera necesario substituir por la masiva llegada de inmigrantes europeos, en un proceso que denominará: "transfusión regeneradora”. Para Bialet Massé, al contrario, la fatiga y el gasto de energía son independientes de cualquier consideración al color de piel.

En ese momento Ingenieros reproduce los discursos difundidos en Europa, que resaltan la pereza de los pueblos llamados "incivilizados". Ingenieros, se inscribe en ese espacio discursivo que Rabinbach define en los siguientes términos:

\begin{abstract}
La ofensiva contra la pereza fue celosamente aplicada tanto a los europeos como a los no europeos. Los etnólogos estaban sorprendidos por el Horror laboris de las "razas incivilizadas", donde "pereza y salvajismo" eran sinónimos. Un etnólogo resumió así la tendencia natural de las poblaciones indígenas de América: "Los norteamericanos como los chilenos, pasan su tiempo en una indolencia estúpida la única felicidad que ellos pueden imaginar es la de no hacer nada. Pasas días enteros recostados en sus hamacas o sentados en el piso, sin cambiar de posición, sin mover los ojos, sin decir palabra Es casi imposible sacarlos de su habitual indolencia Parecen incapaces de cualquier esfuerzo vigoroso". ${ }^{62}$
\end{abstract}

Como veremos Bialet Massé se niega a aceptar y a reproducir estos prejuicios. Reivindica, por el contrario, el derecho que les cabe a los obreros criollos explotados a encontrar y buscar la ocasión para "gozar de la vida, entregándose al amor, a la guitarra, al alcohol”. Y en ese marco se pregunta:

Hábitos de ahorro? Esperanza en el porvenir? En quien recibe un jornal que lleva un déficit de por lo menos el veinte por ciento de lo necesario

62 RABINBACH. The human motor, p. 29. 
para la vida? ( ). La inseguridad, la miseria de la vida no pueden producir sino el deseo del placer del momento: el mañana no existe para quien no espera mejorar. ${ }^{63}$

Sin embrago, es en el marco de la ofensiva contra la pereza, definido por Rabinbach que debemos situarnos para comprender el modo como Ingenieros observa a los nativos y mestizos, apropiándose de discursos elaborados por etnógrafos e intelectuales europeos que hablaban de la pereza reinante en los trópicos. Ingenieros traslada estos enunciados a un contexto absolutamente ajeno a las urgencias económicas y políticas de los países que los habían producido con el claro de construir una justificación pretendidamente para sus aventuras colonialistas.

Ingenieros conocía el Tratado de Geografía y Estadística Médica de Boudin, y otros escritos de geografía médica. El texto denominado La formación de la raza argentina, ${ }^{64}$ es compatible con argumentos similares a los defendidos por Boudin. Ambos afirman la imposibilidad de que la raza blanca pueda aclimatarse a los trópicos, y al mismo tiempo, describen a los indígenas y mestizos como un obstáculo para el desarrollo de países de clima templado. Es por eso que, la formación de una raza blanca argentina, libre de la presencia de indígenas y mestizos será un objetivo clave para Ingenieros.

Ese objetivo, que Ingenieros comparte con otros intelectuales y políticos, dio lugar a lo que podríamos llamar una biopolítica de la población, implementada en la Argentina durante esos años. Para Ingenieros: "En las regiones templadas, hay una sustitución gradual de las razas autóctonas por las razas inmigrantes (...) el proceso étnico y sociológico no puede tener éxito en la América tropical, por razones climáticas". ${ }^{65}$ De modo que, la formación de la raza argentina, sería el resultado de la recepción de un amplio contingente migratorio europeo, capaz de encontrar un territorio favorable para su aclimatación.

Ese discurso es presentado por Ingenieros utilizando un lenguaje naturalista con una jerga que podríamos llamar militar, en la medida en que hablará de "conquistas" sucesivas. Refiriéndose a Humboldt, afirmará las siguientes tesis: (1) en las regiones templadas de América, ubicado en las mismas líneas isotérmicas que su país de origen, la raza blanca de origen europeo, más civilizado, han sustituido a las razas autóctonas; (2) en los trópicos, que no se encuentran en las mismas líneas isotérmicas que su país de origen, las razas blancas no pueden sustituir a las razas nativas; (3) como la etnografía habría mostrado hace tiempo, hay una clara superioridad de la raza blanca que viven en climas templados. Y es en ese contexto que debemos situar sus referencias a Brasil:

Brasil lleva a la Argentina dos grandes ventajas, la extensión territorial y la superioridad numérica de la población. El enunciado de sus ventajas no involucra, sin embargo, un pronóstico favorable. El inmenso territorio brasilero es en gran parte tropical. ( ) A estos factores debe agregarse la masa de negros y mulatos que forma el substrato de su población. Admitido que la civilización superior corresponde a la raza blanca, fácil es inferir que la negra debe descontarse como elemento de progreso. Países donde abundan el negro y el indio no pueden preponderar sobre otros donde el negro y el indio son objeto de curiosidad. Tal es el caso de Argentina, libre ya, o poco menos, de razas inferiores. ${ }^{66}$

63 BIALET MASSÉ. Informe sobre el estado de la clase obrera, p. 31.

64 INGENIEROS, José (1915). La formación de la raza Argentina. In: Obras Completas. Buenos Aires: Ed. Mar Océano, 1961.

65 INGENIEROS. La formación, p. 323.

66 INGENIEROS. La formación, p. 50. 
A partir de esas dudosas hipótesis climáticas y raciales, Ingenerios construye la historia de lo que llamará "una transfusión regenerativa". ${ }^{67}$ Ingenieros utiliza estadísticas, gráficos y mapas que se refieren al blanqueamiento provocado por las distintas corrientes migratorias que se han producido después de la colonización. Analiza y compara la población de la región a partir de tres censos, uno realizado en 1869, el segundo en 1895 y tercero en 1914. Las comparaciones entre los censos, cada uno de ellos realizado después de una ola de inmigración europea, lleva a Ingenieros a concluir que la construcción de una raza argentina blanca (libre de razas indígenas y africanas) solo será posible en América Latina en un único territorio, el argentino, dada la capacidad de aclimatación de los europeos al clima templado que predomina en ese país.

Una vez más Ingenieros reproduce, sin reflexión ni distancia crítica, las tesis defendidas por intelectuales europeos. Escritores como Boudin, ${ }^{68} \mathrm{Max}_{\mathrm{N}} \mathrm{Nordau}^{69} \mathrm{y}$ otros representantes de países colonialistas, justificaron la sumisión de los pueblos colonizados a través de una tesis ampliamente difundida a lo largo del siglo XIX, una tesis que denominaré aquí como pesimismo climático. De acuerdo a esta idea, todos los males sociales, incluidas la pereza, las enfermedades incurables o el alcoholismo se agravarían e generalizarían en regiones tropicales debido a factores climáticos vinculados con las altas temperaturas y la abundancia de alimentos. Para Rabinbach

\begin{abstract}
Clima, clase, y pereza fueron considerados como factores estrechamente conectados, afirmándose que: "la pereza es siempre el resultado de climas calientes, frecuentemente por su exuberancia. Las clases sociales más altas, como los pueblos ecuatoriales, persisten en su pereza. En comparación, el frio, al igual que la pobreza, estimula el vigor y la actividad de los otros hombres, que tarde o temprano desplazarán a aquellos dominados por la pereza". Además, la pereza fue vista como causa de enfermedades físicas traídas por la inactividad. ${ }^{70}$
\end{abstract}

Con la reproducción de ese mito europeo, sin la debida contextualización histórica y geográfica, Ingenieros contribuye a consolidar uno de los grandes mitos fundadores de la Argentina como Estado-nación: su supuesta superioridad frente al resto de América Latina, como consecuencia de su clima templado. De acuerdo a esta tesis, ya defendida por Montesquieu ${ }^{71}$ en El Espíritu de las leyes, la abundancia de riquezas naturales existentes en las regiones tropicales llevaría a la pereza, a la inacción y al desinterés de sus habitantes por cuestiones referidas a la política y a la vida en común.

Esa será la tesis central de un texto de Ingenieros denominado La pereza Latino-americana, publicado en 1903 en la Revista Derecho, Historia y Letras de Buenos Aires. Sostiene aquí la misma tesis expuesta por Rabinbach, reiterada incansablemente desde el siglo XVIII cuando Hume enunció que "existen razones para pensar que todas las naciones que viven más allá de los círculos polares o entre los trópicos son inferiores al resto de su especie". Esta idea que podríamos denominar siguiendo a Canguilhem ${ }^{72}$ de una ideología científica, o siguiendo a

67 INGENIEROS. La formación, p. 308.

68 BOUDIN, Jean. Traité de géographie et de statistique médicale. Paris: Baillière, 1857.

69 NORDAU, Max. Degeneration. London: University of Nebrsk Press, 1895.

70 RABINBACH. The human motor, p. 31.

71 MONTESQUIEU. De l'esprit des loix. London: Nourse, 1767.

72

CANGUILHEN, Georges. El conocimiento de la vida. Buenos Aires: Ed. Anagrama, 1976. 
Jaureche, ${ }^{73}$ de una superstición científica, fue repetida sin cuestionamiento por Ingenieros. Así, refiriéndose al germen de la pereza argentina afirma:

El habito colectivo de la pereza surge cuando ciertas condiciones del medio contribuyen a hacerla posible; la excesiva producción natural. Nuestros campos llenos de ganado, que se carnean para vender el cuero a un precio irrisorio, excluían la necesidad de trabajar para comer, esa abundante ganadería sin dueño en la época de la colonia, permitió que la pereza arraigara hondamente en los hombres. ${ }^{74}$

Deriva de aquí el siguiente corolario, el mismo que se repite desde Hume, y que constituye eso que Jaureche define, con humor, como una de las Zonceras argentinas más difundidas: Hay mucha cultura debajo de la nieve..$^{75} \mathrm{El}$ corolario al que llega Ingenieros después de una larga argumentación es: “La actividad o pereza de una raza está en razón directa del esfuerzo requerido para producir los medios de subsistencia. Tal ley es absoluta". ${ }^{76}$

Más aún, para que no queden dudas de que Ingenieros se limita a reproducir un discurso europeo destinado a la justificación de los procesos coloniales, sin la menor crítica, continuará con una afirmación inexplicable: “Todo esto no impide reconocer que la pereza europea es preferible a la hispano-americana. La primera es propia de los pueblos evolucionados y la segunda de los atrasados que tienen pocas superfluidades necesarias". ${ }^{77}$ De lo dicho hasta aquí, Ingenieros concluirá que "la pereza es el rasgo fundamental del carácter criollo". ${ }^{78}$

Como ya fue dicho, todas las esperanzas de Ingenieros estaban depositadas en la constitución de una raza argentina blanca, originada a través de los sucesivos procesos inmigratorios. El sueño de Ingenieros era la creación de lo que denominará una Nueva nacionalidad constituida por descendientes de inmigrantes europeos. Es así que, José Ingenieros se refiere a esa nueva nacionalidad que consideraba en vías de construcción:

\begin{abstract}
Hace treinta años conocimos un ejército compuesto de indígenas sometidos y gauchos, no había blancos en sus filas. () El ejército actual desde la implantación del servicio militar obligatorio, está compuesto por ciudadanos blancos, salvo en regiones todavía muy mestizadas. Asistiendo a un desfile de tropas, creemos mirar un ejército europeo. ( ) Esa es la más firme expresión de la nueva nacionalidad argentina: en vez de indígenas y mercenarios son ciudadanos blancos los que custodian la nación. ${ }^{79}$
\end{abstract}

Vemos aparecer allí otra de las tantas Zonceras argentinas, reproducidas por la elite intelectual de fines del siglo XIX e inicios del siglo XX, aquella que Jaureche denomina: La inferioridad del nativo. ${ }^{80}$ Ese discurso queda plasmado sin ambigüedad en ésta, que será nuestra última referencia a Ingenieros:

Dentro de veinte o cien años las consecuencias serán fáciles de pronosticar. En el territorio argentino, emancipado hace un siglo por el

73 JAURECHE, Arturo. Manual de Zonceras Argentinas. Buenos Aires: Ed. Corregidor, 2012.

74 INGENIEROS, José (1903a). La pereza latinoamericana. In: Sociología Argentina. Buenos Aires: Ed. Elmer, 1961, p. 84.

75 JAURECHE. Manual de Zonceras Argentinas, p. 74.

76 INGENIEROS. La pereza latinoamericana, p. 85.

77 INGENIEROS. La pereza latinoamericana, p. 87.

78 INGENIEROS. La pereza latinoamericana, p. 88.

79 INGENIEROS. La pereza latinoamericana, p. 263.

80 JAURECHE. Manual de Zonceras Argentinas, p. 100. 
pensamiento y la acción de mil o diez mil "euro-argentinos", vivirá una raza compuesta por veinte o cien millones de blancos familiarizados con el baño y la lectura, símbolos de la civilización. En las horas de recreo leerán las leyendas de las extintas razas indígenas y la historia de la mestizada raza colonial, leerán poemas gauchescos renovados por escritores de razas europeas. ${ }^{81}$

Exactamente un año más tarde, Bialet Massé, nos invita a pensar de otro modo el papel del nativo y del obrero criollo al destacar su importancia, sus méritos y su inteligencia. Esos datos son sistemáticamente desconsiderados por la elite intelectual argentina de la cual Ingenieros es representante:

El obrero criollo, menospreciado, tildado de incapaz, se ve como un paria en su tierra, trabajando más, haciendo trabajos en los que es reemplazable, y percibiendo un salario como para no morirse. $Y$ sufre que en un mismo trabajo se le dé un jornal inferior, porque es criollo, a pesar de su superior inteligencia, de su sobriedad y su adaptación al medio, que le permiten desarrollar energías extraordinarias y demostrar resistencias increíbles. ${ }^{82}$

Ocurre que Bialet Massé, a diferencia de Ingenieros, se niega a reproducir en territorio argentino los discursos elaborados en Europa, insistiendo en que es imprescindible conocer las peculiaridades del territorio y de sus habitantes. Afirmando, en fin, que es necesario atreverse a pensar de modo autónomo e independiente. Para Bialet Massé es preciso negarse a aceptar las conclusiones a las que llegan esos sociólogos o economistas que después de un viaje "cinematográfico", adoptan las tesis y los datos obtenidos en Europa, llegando a conclusiones totalmente "fuera del mundo real y escribiendo cosas que hacen reír". ${ }^{83}$ Considera que estudiar los principios elaborados en países con razas, suelos, climas y costumbres diferentes, para aplicarlos al territorio argentino desconsiderando sus condiciones peculiares, siempre e inevitablemente conducirá a engaños y errores.

Todo lo demás es divagar en un torbellino de errores de los que la humanidad debiera sentirse escarmentada, sobre todo en materia social, en que se producen tantas imágenes, al modo de espejos con rugosidades y abolladuras, especialmente en la República Argentina, que se encuentra ya en estado de hacer ciencia y legislación propias, arrancando de sus mismas tradiciones. ${ }^{84}$

Sus observaciones y entrevistas lo llevarán a extraer consecuencias absolutamente contrarias a las de Ingenieros, quien nunca fue mencionado en su Informe. Una vez que ha podido desmitificar la importancia atribuida a la pereza, Bialet Massé dará un paso más, persiguiendo el objetivo de derrumbar otro mito extendido y ampliamente aceptado por la inteligencia argentina: la supuesta pereza del criollo o del nativo.

A diferencia de Ingenieros manifiesta respeto y admiración, reconociendo que existe cierta superioridad del indígena y del criollo sobre los inmigrantes, pues los últimos desconocen el terreno, sus ventajas y dificultades. Así, aunque hoy debamos mirar con distancia crítica su elogio a la obediencia de los nativos

81 INGENIEROS. La pereza latinoamericana, p. 263.

82 BIALET MASSÉ. Informe sobre el estado de la clase obrera, p. 30.

83 BIALET MASSÉ. Informe sobre el estado de la clase obrera, p. 488.

84 BIALET MASSÉ. Informe sobre el estado de la clase obrera, p. 16. 
y mestizos, no es posible desconsiderar sus observaciones atentas, destinadas a mostrar la capacidad del criollo y el nativo para aprender cualquier oficio rápidamente, el cuidado estético con que realizan su trabajo, la atención con los detalles, su capacidad de concentración, y la rapidez e inteligencia que aplican para resolver problemas complejos. Su interés por la pereza, tiene el objetivo único de "desnaturalizarla", de desvanecer prejuicios profundamente arraigados en ese momento, entre intelectuales que gozan de amplio reconocimiento.

Tal es, entre otras, la preocupación de la inferioridad del obrero criollo, cuando, en verdad, por su fuerza muscular y por su inteligencia, revela una superioridad notable, y la experiencia del taller, del ferrocarril y de la agricultura demuestran que no es extraño ni refractario a ningún arte ni oficio, y que sus defectos y vicios provienen de causas que le son perfectamente extrañas, y cesan con la causa que los produce. ${ }^{85}$

Si Bialet Massé puede observar estas situaciones cotidianas y concretas es porque el problema de la pereza y la moralización de la pobreza por la disciplina laboral, han dejado de ser un problema para él. Centrándose en la cuestión de la fatiga, un hecho fisiológico que sufre tanto el cuerpo del indígena como el cuerpo del inmigrante sometido a esfuerzos reiterados, y después de realizadas las observaciones, pertinentes, llega a las conclusiones siguientes:

1. ${ }^{\circ}$ el error y falta de fundamento del menosprecio con que se ha mirado al obrero criollo; $2 .^{\circ}$ el error gravísimo con que se ha procedido y procede en materia de inmigración y colonización, atendiendo exclusivamente el elemento extranjero, dejando de lado al criollo, mucho más eficaz y valioso; y $3 .^{\circ}$ la necesidad de legislar al hijo del país, mirando a su desarrollo y bienestar, haciendo partícipe al huésped de las ventajas acordadas al criollo, pero no dándole otras que a éste no se concedan. ${ }^{86}$

La preocupación por desmontar los prejuicios contra los criollos recorre todo el Informe de Bialet Massé, desde la introducción hasta las conclusiones. Y es a ese tema que están dedicadas las últimas páginas del Informe, Massé realiza allí una lectura que, lamentablemente, aún no ha perdido actualidad. Indica que el desprecio con el que se observa al criollo, al hombre o a la mujer de piel oscura, no es algo sin consecuencias para la construcción de sus identidades. En un análisis que hoy podemos leer a través de Goffman, ${ }^{87}$ Bialet Massé explica las constantes situaciones de estigmatización a las que están sometidos estos sujetos, en la medida en que todo lo malo que aparece en la sociedad encuentra el calificativo aplastante de "criollo'.

Así quien se embriaga es el criollo, nunca el inmigrante, quien siente pereza es el criollo y no el europeo, quien mendiga o pide limosna es el criollo y nunca el extranjero. Esto es una flagrante tergiversación de la realidad. Todos los días se lee y se oye, dirá Bialet Massé, que este pueblo no tiene remedio, aún cuando, como ha podido demostrar en su Informe, sea superior en calidad y fuerza. El estigma no se limita a lo enunciativo, sino que penetra más profundamente en el tejido social, de modo que puede considerarse natural que el salario del criollo sea menor que el salario del inmigrante europeo, aunque este pudiera hacer mejor su trabajo. Su nacionalidad y su origen los degradaba, y nadie parecía querer entender que

85 BIALET MASSÉ. Informe sobre el estado de la clase obrera, p. 18.

86 BIALET MASSÉ. Informe sobre el estado de la clase obrera, p. 19.

87 GOFFMAN, Erving. Estigma. Notas sobra a manipulação da identidade deteriorada. Rio de Janeiro: Ed. LTC, 1988. 
lo que todo esto producía era "el menosprecio de sí y de lo propio; pues nadie puede apreciar a los demás si no tiene el aprecio de sí y de lo suyo". ${ }^{88}$ Goffman nos auxilia hoy a entender el proceso de construcción de identidades deterioradas, que inevitablemente tendrá efectos duraderos sobre quienes están obligados a convivir con un estigma.

Aún hoy resuenan ecos del viejo sueño de blanqueamiento racial, tan deseado por Ingenieros, cada vez que la Argentina se define como un país de inmigrantes. Entonces, parece olvidar que, hoy como a inicios del siglo XX, las tareas más penosas, los trabajos menos calificados y las filas de desempleados, están mayoritariamente constituidas por habitantes de piel oscura, descendientes de indígenas, mestizos o criollos, quienes, ciertamente, constituyen la mayor parte de la población argentina.

Recebido em 28/03/2015 Aprovado em 23/08/2015 